\title{
New Caspases' inhibitors belonging to the serpin superfamily: A novel key control point of apoptosis in mammalian tissues
}

\author{
Mohammed Gagaoua $^{1 *}$, Yasmine Boudida ${ }^{1 *}$, Samira Becila ${ }^{1}$, Brigitte Picard ${ }^{2}$, Abdelghani Boudjellal ${ }^{1}$, \\ Miguel Sentandreu ${ }^{3}$, Ahmed Ouali ${ }^{4 \#}$ \\ ${ }^{1}$ INATAA, Université de Constantine, Constantine, Algeria \\ ${ }^{2}$ UMR1213 Herbivores, URH-AMUVI, INRA de Clermont Ferrand Theix, St. Genès Champanelle, France \\ ${ }^{3}$ Instituto de Agroquímica y Tecnología de Alimentos, Valencia, Spain \\ ${ }^{4}$ UR370, QuaPA, INRA de Clermont Ferrand Theix, St. Genès Champanelle, France \\ Email: " ouali@clermont.inra.fr
}

Received 16 August 2012; revised 23 September 2012; accepted 3 October 2012

\begin{abstract}
The present report overviews a new family of bovine serpins able to inhibit pseudo-irreversibly initiator and effector caspases, a group of cysteine proteases in charge of cell dismantling during apoptosis, a finely regulated cell death process. The 8 members identified at the gene level showed a high homology with human SERPINA3 and were therefore designed bovSERPINA3-1 to A3-8. At least six of them are able to inhibit caspases. Two of them (bovSERPINA3-1 and A3-3) have been purified from bovine muscle and extensively investigated during these last years. After a general presentation of the serpin superfamily, the kinetic aspects of their interaction with human caspases 3 and 8 were studied and findings obtained suggest that caspases could be their target enzymes in living cells. In muscle and primary myoblast in culture, they showed an intracellular localization and because of their high level in blood, they can be exported. Two biological functions (potential regulator of apoptosis and expression during myoblast differentiation) were investigated and it was concluded that they are very likely an efficient regulator of apoptosis, a proposal supported by their high expression in proliferating myoblast (cell survival is essential during this differentiation phase) but not in myotubes.
\end{abstract}

Keywords: Serpins; Caspases; Apoptosis; Myoblast Differentiation; Bovine

\section{INTRODUCTION}

Apoptosis is a fundamental process in the development

\footnotetext{
* These two authors contributed equally to the work and to this report.

${ }^{*}$ Corresponding author.
}

and maintenance of multicellular organisms and its complex regulation [1] and is commonly not functional in human cancers and some other pathologies related to apoptosis dysfunction [2]. In this respect, the ratio of antiapoptotic molecules to proapoptotic molecules might be more important than absolute amounts of each of them [3]. At the molecular level, the apoptotic cell death machinery forms a complex cascade of ordered events, controlled by the regulated expression of apoptosis-associated genes and proteins. It is the concerted action of these components that finally results in cell dismantling [1]. The key components of this self-destruction machinery are members of the caspase family, a group of cysteine peptidases classified apart from peptidases of the papain family. As suggested in [4], caspase inhibitors are one of the most important control points, if not the control point, for apoptosis execution. Naturally occurring caspase inhibitors include seven members of the mammalian IAP (inhibitors of apoptosis proteins) family. The mode of inhibition of caspases by IAPs greatly differ from the traditional mechanisms known for cystatins, serpins and other peptidase inhibitors families mostly interacting with their target peptidase in a substrate-enzyme manner. By contrast, binding with relatively low affinity (Kd in the $\mu \mathrm{M}$ range) of IAPs in the vicinity of the active site creates a sufficient steric obstruction to prevent access of the active site to protein substrates, small peptide substrates being hydrolysed after IAPs binding $[1,4,5]$. The anti-apoptotic function of the IAP proteins family can be cancelled by specific inhibitors of this interaction, i.e. Smac/DIABLO and Omi/HtrA2 proteins [6]. In human, the only one other natural caspase inhibitor identified so far was the proteinase inhibitor 9 (PI9) which inhibits weakly and slowly caspase 1 with a $\mathrm{k}_{\text {ass }}$ of $7 \times 10^{2} \mathrm{M}^{-1} \cdot \mathrm{s}^{-1}$ suggesting that it will not be 
physiologically efficient [7].

We report here the general properties and potential biological functions of a group of serpins, identified in bovine skeletal muscle and able to inhibit strongly and pseudo-irreversibly human initiator and effector caspases. This is the first time that mammalian tissues were shown to express pseudo-irreversible caspases inhibitor belonging to the serpin superfamily.

\section{GENERAL PROPERTIES OF SERPINS}

\subsection{The Serpin Superfamily}

Serpins are a group of proteins with similar structure that were first identified as a set of proteins able to inhibit proteases. The acronym "SERPIN" was originally coined because many serpins inhibit serine proteases (SERine Protease INhibitors). Over 3000 serpins have now been identified; these include 36 human proteins, as well as molecules in plants, fungi, bacteria, archaea and certain viruses [8]. Serpins are thus the largest and most diverse family of protease inhibitors.

While most serpins control proteolytic cascades, certain serpins do not inhibit enzymes, but instead perform diverse functions such as storage (ovalbumin), hormone carriage proteins (Thyroxine-Binding Globulin) and tumor suppressor genes (maspin). The term "SERPIN" is used to describe these latter members as well, despite their non-inhibitory function. Inhibitory serpins were later shown to be cross-class inhibitors since they are able to inhibit other groups of proteinases especially cysteine peptidases $[9,10]$.

Inhibitory serpins are generally highly metastable proteins comprising several $\alpha$-helix and $\beta$-strands together with an external reactive center loop (RCL) containing the active site recognized by the target enzyme (Figure 1(a)) [11]. The sequence of the RCL defines the enzyme specificity pattern of each serpin. All inhibitory serpins are irreversible covalent "suicide" protease inhibitors forming a highly stable covalent complex with their target enzyme, a complex detectable after gel electrophoresis in denaturing conditions $[9,12,13]$. A large set of information together with the serpin classification are also available at the following web site:

http://en.wikipedia.org/wiki/Serpins.

\subsection{Structural Features}

As shown in Figure 1(b) for $\alpha_{1}$-antitrypsin or SERPINA1, upon cleavage of the RCL, the serpin adopt quickly a more stable conformation by insertion of the RCL within the $\beta$-strand series [14]. This property is essential to the irreversible suicide substrate inhibitory mechanism of serpins. In the inhibitory pathway, the proteinase forms a non-covalent Michaelis-like complex (Figure 1(c)) through interaction with residues flanking the scissile bond (P1-P1') [15]. Attack of the active site serine on the scissile bond leads to a covalent ester linkage between highly reactive "Ser" residue of the proteinase and the backbone carbonyl of the $\mathrm{P} 1$ residue and cleavage of the peptide bond. It is likely that only at this stage, with removal of the restraint, does the RCL start to insert into $\beta$-sheets and transport the covalently bound proteinase with it. Upon complete loop insertion the proteinase is translocated to the distal side of the serpin (Figure 1(d)) [16]. This translocation induced an important distortion of the proteinase which became unable to complete the catalytic process. The energy needed to effect the distortion may come from the much greater stability of the cleaved loop-inserted conformation compared with the native-like conformation.

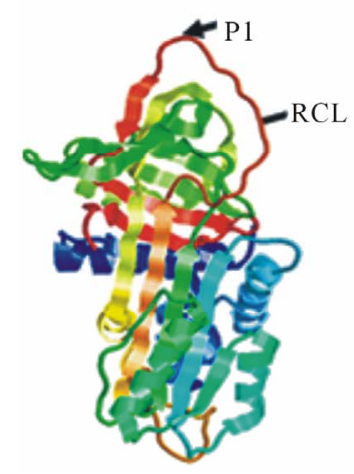

(a)

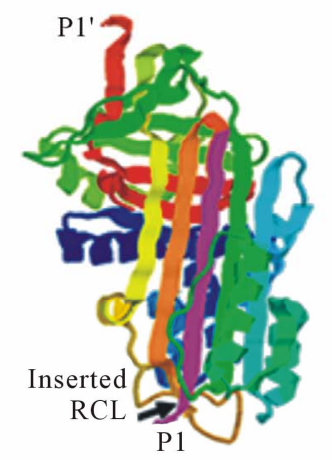

(b)

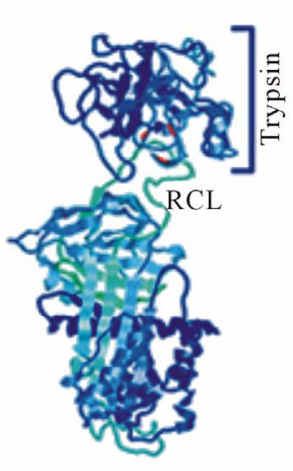

(c)

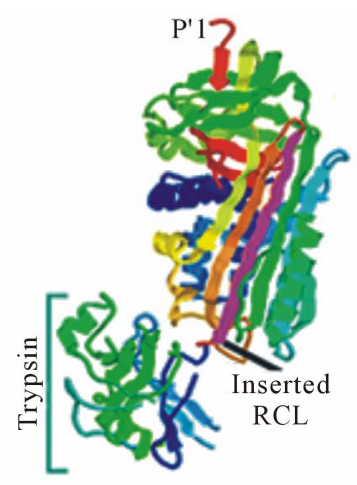

(d)

Figure 1. Serpin structures and conformation. (a) Native $\alpha_{1}$-AT (Protein Data Bank (PDB) entry 1QLP) [11]; (b) Cleaved $\alpha_{1}$-AT (PDB entry 7API): Upon RCL cleavage, the loop inserts into the serpin core constituting an additional strand [14]; (c) Michaelis complex between Serpin A1 (Alaserpin from Manducasexta) and trypsin (PDB entry 1I99 [15]; (d) Covalent complex between $\alpha_{1}$-AT and trypsin (PDB entry 1EZX). The enzyme is transported to the distal part of the serpin and undergoes an irreversible deformation responsible of the enzyme inactivation [16]. In (b) and (d) the inserted RCL is in purple. AT, antitrypsin or serpin A1. 


\subsection{Analysis of Protease-Serpin Interactions}

Given the general mechanisms reported so far, kinetic values are determined under the assumption that inhibittion is irreversible. In such case, the inhibition constant (Ki) is of no interest and will bring no information about the enzyme-serpin interaction. The major macroscopic parameters that define the effectiveness of serpin inhibition of a particular target protease are the stoichiometry of interaction (SI) and the apparent second order rate constant of inhibition $\left(\mathrm{k}_{\mathrm{ass}}\right)$. Another parameter can be the stability of the covalent complex during the inhibition process often characterized by SDS-PAGE analysis, the complex being stable in the presence of SDS even after heating in boiling water.

\section{BOVINE CASPASE INHIBITING SERPINS: KINETIC OF INTERACTION}

The two first 70 and $75 \mathrm{kDa}$ serpins able to inhibit strongly initiator (caspase 8) and effector (caspase 3) caspases [17] were purified from bovine skeletal muscle as previously reported $[18,19]$ and characterized. These were designed bovSERPINA3-1 (Swiss Prot ID: Q9TTE1) and bovSERPINA3-3 (Swiss Prot ID: Q3ZEJ6) [20] according to the established nomenclature recommendations [9]. Because of their high homology with human $\alpha_{1}$-antichymotrypsin or SERPINA3 $(\approx 75 \%)$ they were assumed to belong to this group of serpin and called bovSERPINA3-1 or A3-3. Their activity was tested against a large set of serine and cysteine proteases including bovine pancreatic trypsin; Human leukocyte elastase (HLE) and cathepsin G; bovine plasma chymotrypsin, plasmin and thrombin; Human kidney cells urokinase; Tissue Plasminogen Activator from human melanoma cells; porcine pancreatic kallikrein; papain; bovine liver cathepsins $\mathrm{B}$ and $\mathrm{L}$; bovine muscle calpains and recombinant human caspases 3 and 8 and both SI and $\mathrm{k}_{\text {ass }}$ were determined for all strongly inhibited proteases.

\subsection{Stoichiometry of Interaction with the Susceptible Peptidases}

The stoichiometry of interaction was determined by titration of the target enzymes (HLE, trypsin, caspases 3 and 8) with increasing amounts of either bovSERPINA3-1 or A3-3 as in [21]. As shown in Table 1, total inhibition of trypsin and human leukocyte elastase was achieved using equimolar concentrations of either serpins suggesting a 1:1 interaction ratio.

Regarding caspases, analysis of the findings of Table 1 needs to remind that each molecule of caspases is a tetrameric structure comprising two associated moieties composed of a large and a small subunit, each moiety
Table 1. Stoichiometry of interaction of bov-serpins with the target enzymes: bovine pancreatic trypsin, Human Leukocyte Elastase (HLE), human recombinant caspases 3 and 8.

\begin{tabular}{ccc}
\hline & \multicolumn{2}{c}{ Stoichiometry of interaction } \\
\cline { 2 - 3 } & SerpinA3-1 & SerpinA3-3 \\
\hline Trypsin & $1.01 \pm 0.03$ & $0.98 \pm 0.01$ \\
HLE & $1.04 \pm 0.02$ & $1.01 \pm 0.03$ \\
Caspase 3 & $1.01 \pm 0.07$ & $0.55 \pm 0.07$ \\
Caspase 8 $^{\mathrm{a}}$ & $0.49 \pm 0.09$ & $0.51 \pm 0.06$ \\
\hline
\end{tabular}

${ }^{\mathrm{a}} \mathrm{SI}=[\mathrm{I}] /[$ Caspase active sites $]$.

containing an active site, i.e. two active sites in each native caspase. An equimolar interaction (1 mole of inhibittor per active site) was thus observed for the inhibition of caspase 3 by bovSERPINA3-1. That means that, for total inhibition of the caspase, one molecule of bovSERPINA3-1 must bind to each active site of caspase 3. In all other cases, namely inhibition of caspases 3 and 8 by bovSERPINA3-3 or inhibition of caspase 8 by bovSERPINA3-1, one mole of inhibitor inactivates simultaneously the two active sites ( 0.5 mole of inhibitor per active site) suggesting that association of the inhibitor to one of the two active sites induces a sufficient allosteric conformational change of the homodimeric peptidase to make the second site unable to bind substrates.

\subsection{Association Rate Constant towards Different Cysteine and Serine Proteases}

Apparent Association rate constant ( $\mathrm{k}_{\text {app }}$ ) was measured according to the discontinuous method for enzymes interacting slowly with the serpins $\left(k_{\text {app }} \leq 10^{4} \mathrm{M}^{-1} \cdot \mathrm{s}^{-1}\right)$ whereas the continuous method was used for rapid enzyme/serpin interaction as in [21]. The association rate constant is then determined according to Eq.1:

$$
\mathrm{k}_{\text {ass }}=\mathrm{k}_{\text {app }} * \mathrm{SI}
$$

For fast serpin/enzyme interaction, the apparent association constant determined by the continuous method was finally determined according to Eq.2:

$$
\mathrm{k}_{\text {ass }}=\mathrm{k}_{\text {app }}(1+[\mathrm{S}] / \mathrm{Km}) * \mathrm{SI}
$$

where $[\mathrm{S}]$ is the substrate concentration used for activity measurement and $\mathrm{Km}$ the Michaelis constant characterizing the affinity of the protease towards the substrate.

As depicted in Table 2, bovSERPINA3-1 and bovSERPINA3-3 showed a similar pattern towards the proteinases tested. No inhibition was detected against five of the serine peptidases tested including Cathepsin G, Kallikrein, Urokinase, Plasminogen activator and Thrombin. By contrast, bovSERPINA3-1 and A3-3 are able to 
Table 2. Association rate constant $\left(\mathrm{k}_{\mathrm{ass}}\right)$ determined for the most sensitive proteases. Significant $\mathrm{k}_{\mathrm{ass}}$ are in bold.

\begin{tabular}{ccc}
\hline \multicolumn{3}{c}{ Association rate constant $\left(\mathrm{k}_{\text {ass }}\right)\left(\mathrm{M}^{-1} \cdot \mathrm{s}^{-1}\right)$} \\
\hline & bovSERPINA3-1 & bovSERPINA3-3 \\
\hline Trypsin & $3.9 \times 10^{6}$ & $6.7 \times 10^{5}$ \\
Chymotrypsin & $1.0 \times 10^{2}$ & $9.0 \times 10^{2}$ \\
Plasmin & $1.8 \times 10^{3}$ & $2.7 \times 10^{3}$ \\
Elastase & $2.4 \times 10^{7}$ & $1.3 \times 10^{6}$ \\
Caspase 3 & $4.2 \times 10^{5}$ & $1.5 \times 10^{5}$ \\
Caspase 8 & $1.4 \times 10^{6}$ & $2.7 \times 10^{6}$ \\
\hline
\end{tabular}

inhibit strongly elastase $\left(\mathrm{k}_{\text {ass }}=1.3 \times 10^{6} \mathrm{M}^{-1} \cdot \mathrm{s}^{-1}\right)$ and trypsin $\left(\mathrm{k}_{\text {ass }}=6.7 \times 10^{5} \mathrm{M}^{-1} \cdot \mathrm{s}^{-1}\right)$ while chymotrypsin and plasmin were only slightly inhibited and the $k_{\text {ass }}$ values obtained for these two last enzymes are not of physiological significance $[18,19]$.

As serpins are able to inhibit some cysteine proteases, bovSERPINA3-1 and A3-3 were tested against papain like enzymes including cathepsins B \& $\mathrm{L}$ and papain itself and against calpains 1 and 2, two calcium dependant cysteine peptidases. Neither of these cysteine proteases was inhibited by the present serpins $[18,19]$.

Bovine serpins were also tested against a group of cysteine peptidases called caspases. The first letter of the name " $C$ " stands for the cysteine of the active site; "asp" defines the strict specificity of cleavage after an aspartic acid residue and ase is the suffix common to all enzymes. These are responsible of cell dismantling during apoptosis, a finely regulated cell death process and according to their function in the cell dying process, they were classified as initiator (caspases 8,9 and 10) and effector (caspases 3, 6 and 7) caspases, initiator caspases being in charge of the limited proteolytic activation of effector ones. Caspase 8, an initiator caspase, and caspase 3, an effector caspase, are strongly inhibited by both serpins (Table 2) and $\mathrm{k}_{\text {ass }}$ values are in the range of $10^{5}-10^{6}$ $\mathrm{M}^{-1} \cdot \mathrm{s}^{-1}$ indicating that this inhibition is of high physiological significance [17].

Interestingly, these were the first mammalian serpins identified as strong inhibitor of human initiator and effector caspases and able to form SDS-stable complexes with these proteinases [19]. The only one other serpin found to inhibit caspases is crmA (Cytokine response modifier A) isolated from cowpox virus and unable to form SDS-stable complexes with caspases. Complexes were revealed only upon non denaturing polyacrylamide gel electrophoresis (Native-PAGE) [23]. In infected cells, crmA is suspected to block the apoptotic process during multiplication of the virus $[23,24]$.

\subsection{Ability to Form SDS-Stable Complexes with Their Target Enzymes}

Serpin inhibition of cysteine proteases proceeds according to the same trapping mechanism than for serine proteases [25]. Upon SDS-PAGE, we could therefore expect to identify the covalent complexes for all proteases shown to be strongly inhibited by bovSERPINA3 isoforms. As illustrated in Figure 2 for bovSERPINA3-1, bovine serpins $(70 \mathrm{~K})$ are thus able to form SDS-stable complexes (C) with bovine pancreatic trypsin, human leukocyte elastase, human caspase 3 (apoptosis effector caspase) and human caspase 8 (apoptosis initiator caspase) [17-19].

Regarding caspases 3 and 8, preincubation of these enzymes with bovSERPINA3-1 leads to an SDS-stable complex of about $106 \mathrm{kDa}$. According to the $\mathrm{Mr}$ value, the complexes would comprise the cleaved inhibitor (70 $\mathrm{kDa})$ and the covalently bound caspase $(\approx 30 \mathrm{kDa})$ transported to the distal pole of the serpin. The covalently bound caspase is very likely an heterodimeric moiety (with or without the small subunit) of the tetrameric molecule, the other moiety being very likely dissociated during heat denaturation of the sample in the presence of SDS. Further investigations are needed to clarify the exact mechanisms of the caspase/bovSERPINA3 complex formation and the behaviour of caspase subunits during complex formation [17]. Note that in Figure 2, the 140 $\mathrm{kDa}$ band observed for all peptidases corresponds to a dimer of the serpin as assessed by $\mathrm{N}$-terminal sequence analysis [18]. Similar findings were obtained with bovSERPINA3-3 (results not shown).

\section{CELLULAR LOCALIZATION AND TISSUE DISTRIBUTION}

Immunolocalization of bovSERPINA3-1 was performed on transverse sections of freshly excised adult bovine Longissimus muscle and in proliferationg primary bovine

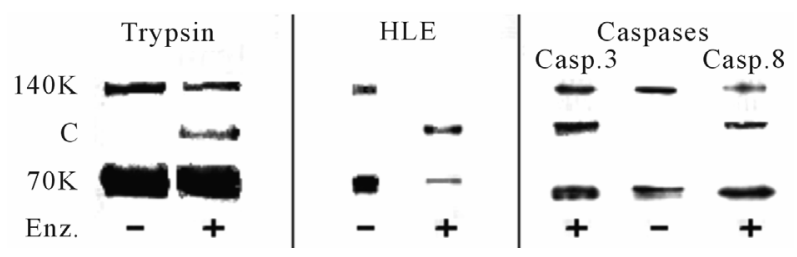

Figure 2. Covalent complexes upon SDS-PAGE between bovSERPINA3-1 and proteases as revealed by western blot, using the rabbit polyclonal antibody raised against this serpin [17]. Similar findings were obtained with bovSERPINA3-3 (not shown). Note that the $140 \mathrm{kDa}$ band is a dimer of the 70 kDaserpin [18]. C, band corresponding to the complex formed with the different target enzymes: trypsin, Human Leukocyte Elastase (HLE) and human recombinant caspases 3 and 8. (-) inhibitor alone; $(+)$ inhibitor incubated with the target enzyme (Enz). 
myoblast using a specific polyclonal rabbit antiserum. As depicted in Figure 3(a), the muscle serpin is highly concentrated between the plasma membrane and the myofibrils, whereas lower fluorescence intensity can be seen within the myofibrils in the centre of muscle fibers, indicating that muscle serpin is exclusively intracellular with a preferential peripheral localization. No fluorescence was detected in the control sample for which the primary antibody was omitted (Insert of Figure 3(a)). In primary bovine myoblast (Figure 3(b)), a cytoplasmic localization was also noted and no fluorecence was observed within the nucleus comforting the intracellular localization observed in skeletal muscle.

Tissue distribution and content of bovSERPINA3-1 and other closely related serpins (see below) was assessed by ELISA (Enzyme Linked ImmunoSorbant Assay) in different bovine tissues and fluids including bovine plasma, liver, kidney and bovine diaphragma muscle. According to the results presented in Table 3, this serpin is very abundant in plasma $(\approx 1 \mathrm{mg} / \mathrm{ml})$ as compared to liver (14 $\mu \mathrm{g} / \mathrm{g}$ wet tissue), kidney ( $2 \mu \mathrm{g} / \mathrm{g}$ wet tissue) and muscle $(1 \mu \mathrm{g} / \mathrm{g}$ wet tissue). Whether the serpin function is similar inside tissue cells and in blood is still unknown.

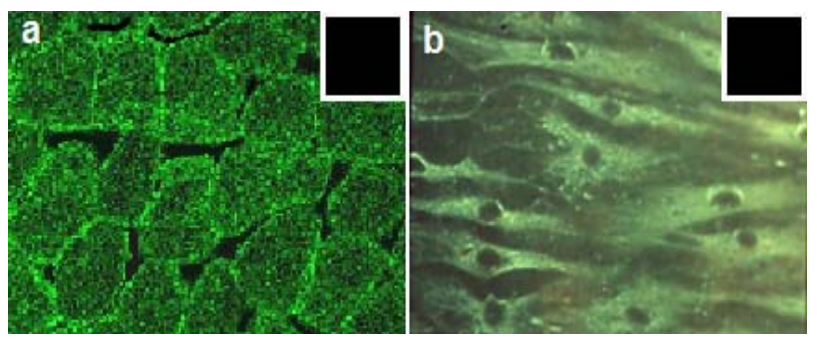

Figure 3. Cellular localization of bov-SerpinA3-1 in transversal cut of bovine skeletal muscle (a) and in primary bovine myoblast culture (b) using the rabbit polyclonal antibody raised against the purified serpin. Inserts are controls for which the primary antibody was omitted.

Table 3. ELISA (Enzyme Linked ImmunoSorbant Assay) quantification of bovSERPINA3-1 in different bovine fluids and tissues. Present NQ, means that the serpin was detected by other method but not quantified [18].

ELISA Quantification of bovSERPINA3-1

\begin{tabular}{cc}
\hline Fluids/Tissues & [bovSERPINA3-1] \\
\hline Plasma & $1.0 \mathrm{mg} / \mathrm{ml}$ \\
Liver & $14 \mu \mathrm{g} / \mathrm{g}$ wet tissue \\
Kidney & $2.0 \mu \mathrm{g} / \mathrm{g}$ wet tissue \\
Muscle & $1.0 \mu \mathrm{g} / \mathrm{g}$ wet tissue \\
Thymus & Present NQ \\
Spleen & Present NQ \\
\hline
\end{tabular}

\section{COMPLEXITY OF} THE BOV-SERPINA3 FAMILY

\subsection{Polymorphism of bovSERPINA3s at the Protein Level}

In the first step of the Purification procedure developed for bovSERPINA3-1 [18], the crude muscle extract was run on a SP-Sepharose column $(5 \mathrm{~cm} \times 10 \mathrm{~cm})$ and proteins were eluted using a $\mathrm{NaCl}$ gradient (Figure 4(a)). Western blot analysis of the fractions collected throughout the $\mathrm{NaCl}$ gradient revealed a cross-immunoreactivity with the antibody raised against the purified serpin, of most if not all fractions (Figure 4(b)). Moreover, the antibody recognized a series of proteins with different Mr, suggesting that the bovSERPINA3 comprised different closely related members.

To confirm this assumption, pooled active fractions FI and FII obtained upon gel filtration of a muscle crude extract and identified in Figure 5(a) were analyzed by 2D gel electrophoresis and proteins revealed with the same anti-bovSERPINA3-1 antibody.

As assessed by western blot, 2D gel electrophoresis of the FI fraction revealed a complex protein pattern with $\mathrm{pI}$ ranging between about $\mathrm{pH} 4$ and 6.8 (Figure 5(b)). It is impossible to determine the number of isoforms but the horizontal alignment of spots towards more acidic $\mathrm{pH}$ supports the presence of various degree of phosphorylation of these serpins (black line with close arrowhead). In addition some spots are distributed in a comma shape manner (arrows) suggesting that a large set of isoforms

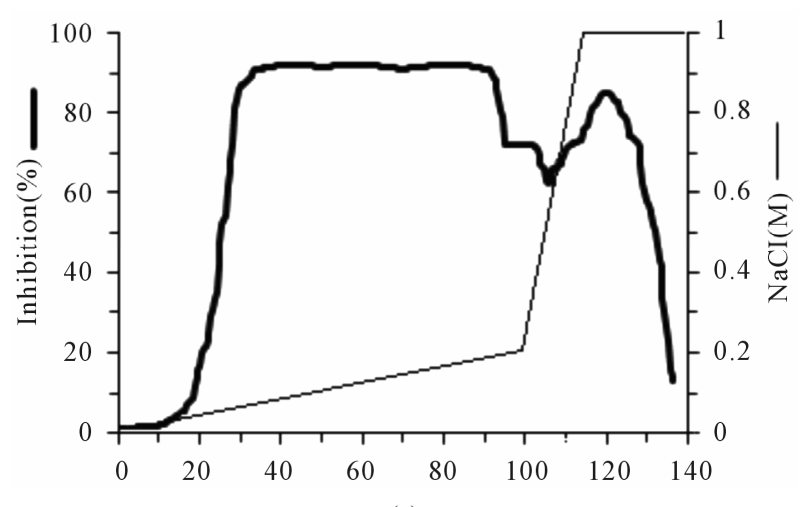

(a)

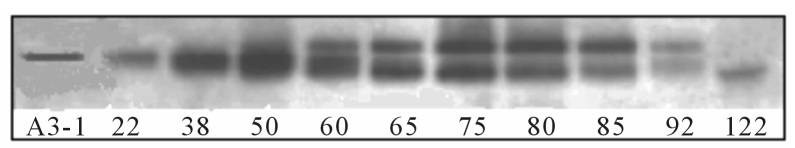

(b)

Figure 4. Polymorphism of the bovSERPIN family as assessed by SDS-PAGE and western blot: (a) Elution profile of a muscle crude extract from a SP-Sepharose column [18]; (b) Western blot analysis of the fractions eluted throughout the $\mathrm{NaCl}$ gradient (fraction number under each lane). As a control the purified bovSERPINA3-1 (70 kDa) was loaded in the first well (A3-1). 


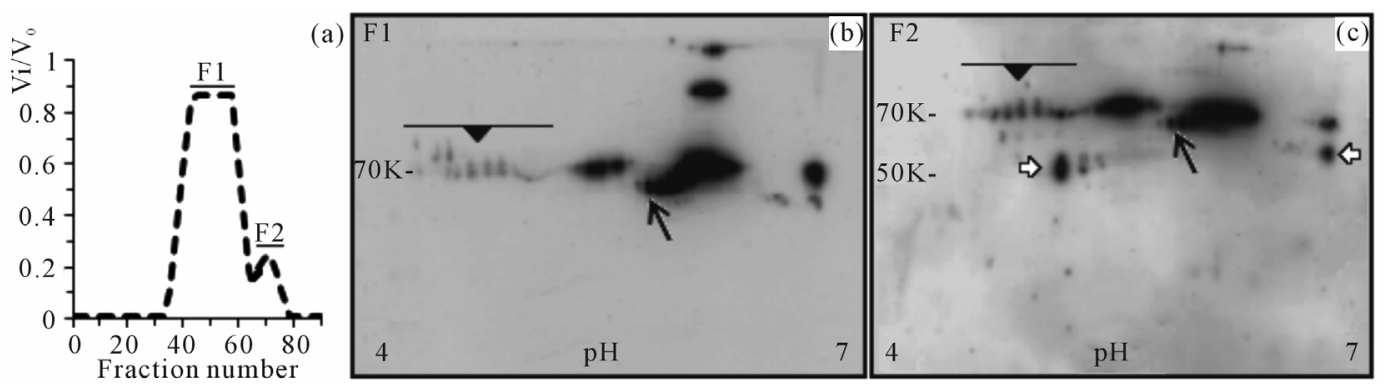

Figure 5. Polymorphism of the Bov-SERPINA3 family as assessed by 2D gel electrophoresis. In the second purification procedure developed for the co-purification of Bov-SerpinA3-1 and A3-3 [19], the first step is a chromatography of the muscle crude extract on a Sephadex G100 column $(5 \mathrm{~cm} \times 100 \mathrm{~cm})$ and the two first fractions eluted were subjected to 2D gel electrophoresis (a). (b) 2D Gel analysis of the F1 fraction. (c) 2D gel analysis of fraction F2. Western blot were performed using the rabbit polyclonal antibody raised against Bov-SerpinA3-1.

are glycosylated to various extents, a feature in good agreement with the overestimated $\mathrm{Mr}$ obtained by gel electrophoresis for both A3-1 and A3-3 (70 and $75 \mathrm{kDa}$ versus $43-44 \mathrm{kDa}$ for the $\mathrm{Mr}$ deduced from the protein sequences). This was confirmed recently by PNGase F (progressive removal of all $\mathrm{N}$-glycans) treatment of recombinant glycosylated bovSERPINA3-3 produced and purified from S. cerevisiae [26]. Such treatment revealed six states of glycosylation corresponding to six different forms of different Mr separated by SDS-PAGE. A similar finding was obtained with purified bovSERPINA3-1 (unpublished data). These results are in good agreement with the five N-glycosylation sites identified in the sequence of this serpin [19].

As compared with fraction FI, fraction FII shows a wholly similar protein pattern plus some additional spots of lower Mr (open arrows in Figure 5(c)). To conclude, all findings obtained so far emphasized the large molecular diversity of the bovine SERPINA3 family which led us to identify the genes encoding these proteins in bovine genome.

\subsection{Genomic Organization of the Bovine Serpin A3 Genes}

Clustering of serpin genes frequently occurs in the genome of human and other animal species. In human, the chromosome 14q32 cluster comprised several serpins genes encoding structurally related proteins with very diverse functions including SERPINA1 ( $\alpha_{1}$-antitrypsin), SERPINA3 ( $\alpha_{1}$-antichymotrypsin), SERPINA5 (PCI, protein $C$ inhibitor), SERPINA9 (centerin), SERPINA10 (ZPI, protein Z-dependent protease inhibitor), SERPINA11 (not characterized yet) as well as SERPINA4 (kallistatin precursor) [27].

In mouse, 14 genes mapped on chromosome 12F1 cluster were identified and encoded for closely related serpins of the SERPINA3 family [28]. Similarly, 6 genes encoding SERPINA3-like were mapped in rat on chro- mosome 6q32 cluster [29], whereas in pork, 6 similar genes were mapped on chromosome 7q23-q26 cluster [30,31].

What about SERPINA3-like serpins' genes in bovine? Based on the first sequence available for bovSERPINA3-1 and A3-3 [19] several probes were designed and used to screen for similar genes in the bovine genome. A cluster of eight genes and one pseudogene sharing a high degree of identity and the same structural organization was characterized [20]. Bovine SERPINA3 genes were localized by radiation hybrid mapping on 21q24 and only spanned over 235 Kilobases. For all these genes, we proposed a new nomenclature from bovSERPINA3-1 to bovSERPINA3-8. They share approximately $75 \%$ of identity with the human SERPINA3 ( $\alpha_{1}$-antichymotrypsin) homologue. Preliminary expression analyses of these bovSERPINA3s showed different tissue-specific patterns and diverse states of glycosylation and phosphorylation, a finding in good agreement with the tissue distribution and the polymorphism of the bovSERPINA3-like assessed at the protein level by different approaches. Hence we concluded that the bovine SERPINA3 family comprised at least eight different proteins members and probably more with regards to their variable degree of post-translational modifications (various degrees of glycosylation and phosphorylation) (see Figure 5).

\subsection{Comparative RCL Sequences and Potential Enzyme Targets}

As mentioned above, the sequence of the RCL defines the enzyme specificity pattern of each serpin. Comparison of the RCL sequences of the eight proteins encoded by the genes mapped on bovine chromosome 21 provides additional information about their structural and functional relationship.

According to the RCL sequences depicted in Figure 6, 3 subgroups can be identified on the basis of their sequence homology. The first one (a) comprises bovSER- 


\begin{tabular}{|c|c|}
\hline (a) & 50 \\
\hline BOVSERPINA3-1 & EEGTEGAAATGISMERTILRIIVRVNRPFIIAIVIKDTQSIIFLGKVTNPSEA \\
\hline BOVSERPINA3-3 & EEGTEGAAATGIGIERTELRIIVRVNRPELIAVVLKDTQSIIFLGKVTNPSEA \\
\hline (b) BovSERPINA3-2 & EEGTEGVAATGIGIERTFLRIIVRVNRPFLIAVVLKDTQSIIFLGKVTNPSEA \\
\hline BovSERPINA3-4 & EEGTEGAAATGIGIERTFLRIIVRVNRPFLIAVVLKDTQSIIFLGKVTNPSEA \\
\hline BovSERPINA3-5 & EEGTEGAAATGIGIERTELRIIVRVNRPFIIAVVIKDTQSIIFLGKVTNPSEA \\
\hline BovSERPINA3-6 & EEGTEGAAATGIGIERTELRIIVRVNRPELIAVVLKDTQSIIFLGKVTNPSEA \\
\hline (c) BOVSERPINA3-7 & EEGTEGAAVTAVVMATSSLLHTLTVSFNREFLLSIFCKETQSIIFLGKVTNPKEA \\
\hline BOVSERPINA3-8 & EEGTEGAAATGVKVGITSINNHIPLSENRPFLIA IVLKDTQSI IFLGKVTNPSQA \\
\hline
\end{tabular}

Figure 6. Alignment of RCL sequences of bovSERPINA3-1 to bovSERPINA3-8. (a) Reactive Centre Loop (RCL) sequences of bovSERPINA3-1 and A3-3 used throughout this work; (b) RCL sequence with highest similarities with bovSERPINA3-1; (c) RCL sequence of the most divergent bovSERPINA3-7 and A3-8. Residues in white bold type indicate $\mathrm{P} 1$ residues for trypsin $\left(\mathrm{Arg}^{16}\right)$ and putative P1 residue for caspases 3 and 8 ( $\mathrm{Asp}^{37}$ for $\mathrm{A} 3-1$ to $\mathrm{A} 3-6$; $\mathrm{Glu}^{39}$ and $\mathrm{Asp}^{39}$ for $\mathrm{A} 3-7$ and $\left.\mathrm{A} 3-8\right)$.

PINA3-1 and A3-3 which have been used throughout the present studies. The second (b) comprises all serpins showing the highest homology with bovSERPINA3-1 and able to inhibit trypsin (bov-SerpinA3-2 and A-3-4 to A3-6). All have an Arg (white on black bold letter R) residue at position 16 of the RCL and a Thr residues at position 17 (bold underlined T), two amino acid residues susceptible to explain their ability to inhibit strongly trypsin and elastase.

The second group would comprise the two last serpins, namely bovSERPINA3-7 and A3-8, which have no Arg residues in similar position and would be unable to inhibit trypsin. By contrast, they both exhibit a Thr residue at position 16 and 17 and a Ser residue at position 17 and 18 , respectively, suggesting that they will be able to inhibit elastase. This has been recently verified for bovSERPINA3-7. Position of the P1 residues identified as preferential cleavage sites for trypsin and elastase agrees well with the supposed invariable RCL length value of about 17 amino acids.

As suggested in their name, caspases cleaved polypeptides essentially at the carboxyl side of Asp residues. No other potential P1 residues are actually known. On the other hand we found that purified bovSERPINA3-1 and A3-3 are strong inhibitors of caspases 3 and $8\left(\mathrm{k}_{\text {ass }}>10^{5}\right.$ $\left.\mathrm{M}^{-1} \cdot \mathrm{s}^{-1}\right)$. The only one Asp residue in bovSERPINA3-1 to A3-6 RCL susceptible to be targeted by both caspases is $\mathrm{Asp}^{37}$ is far beyond the $17^{\text {th }}$ residue corresponding to the maximum length requested for serpin efficiency. bovSERPINA3-7 contains no Asp residue in its RCL while one Asp residue is observed at position 39 in bovSERPINA3-8. These observations strongly suggest that bovSERPINA3-1 to A3-6 would be able to inhibit caspases and to form SDS-stable complexes with them. Whereas bovSERPINA3-7 will not be able to inhibit caspases since no Asp residue can be found in the RCL sequence, the ability of bovSERPINA3-8 to inhibit these cysteine tetrameric proteases would seem possible but this assumption needs to be tested experimentally. By contrast, these last serpins are very likely able to inhibit elastase for which the P1 residue would be very likely
Thr at position 16 for bovSERPINA3-7 and 17 for bovSERPINA3-8.

Regarding caspases, the present findings are therefore in total contradiction with the RCL length invariance of serpins established with various monomeric targeted serine proteases (trypsin, elastase...). Caspases are tetrameric cysteine proteases containing two active sites and whether the rule can be different for serpin interaction with these much larger proteases is questionable and calls for further clarification.

\section{POSSIBLE BIOLOGICAL FUNCTIONS OF BOVSERPINA3}

Because of their ability to strongly inhibit caspases, two functions will be considered here because of the potential implications of cell death in these processes but this list is obviously not exhaustive and needs refinement.

The first is of course apoptosis (Figure 7) which is the primary process of concern with regards to the presently discovered function for these inhibitors. The second is the differentiation of muscle cells for which a resistance to cell death has often been reported in the first stages corresponding to the proliferation and confluence of myoblast. In addition, because of their probable implication in cell survival, proliferation and differentiation [32], caspases could be the potential targets for such a function in myoblast differentiation.

\subsection{BovSERPINA3: A New Control Point of Apoptosis in Mammals}

Since the 80 's, it is well established that for most proteolytic systems, if not all, natural peptidase inhibitors constitute the major tool for controlling their biological activity. Regarding caspases, the first regulation level involves the conversion of zymogens to their active forms in response to inflammatory or apoptotic stimuli. This conversion is generally ensured by association of the peptidases with specified protein activator complexes.

The second level of regulation involves the specific inhibition of active caspases by natural inhibitors. To 


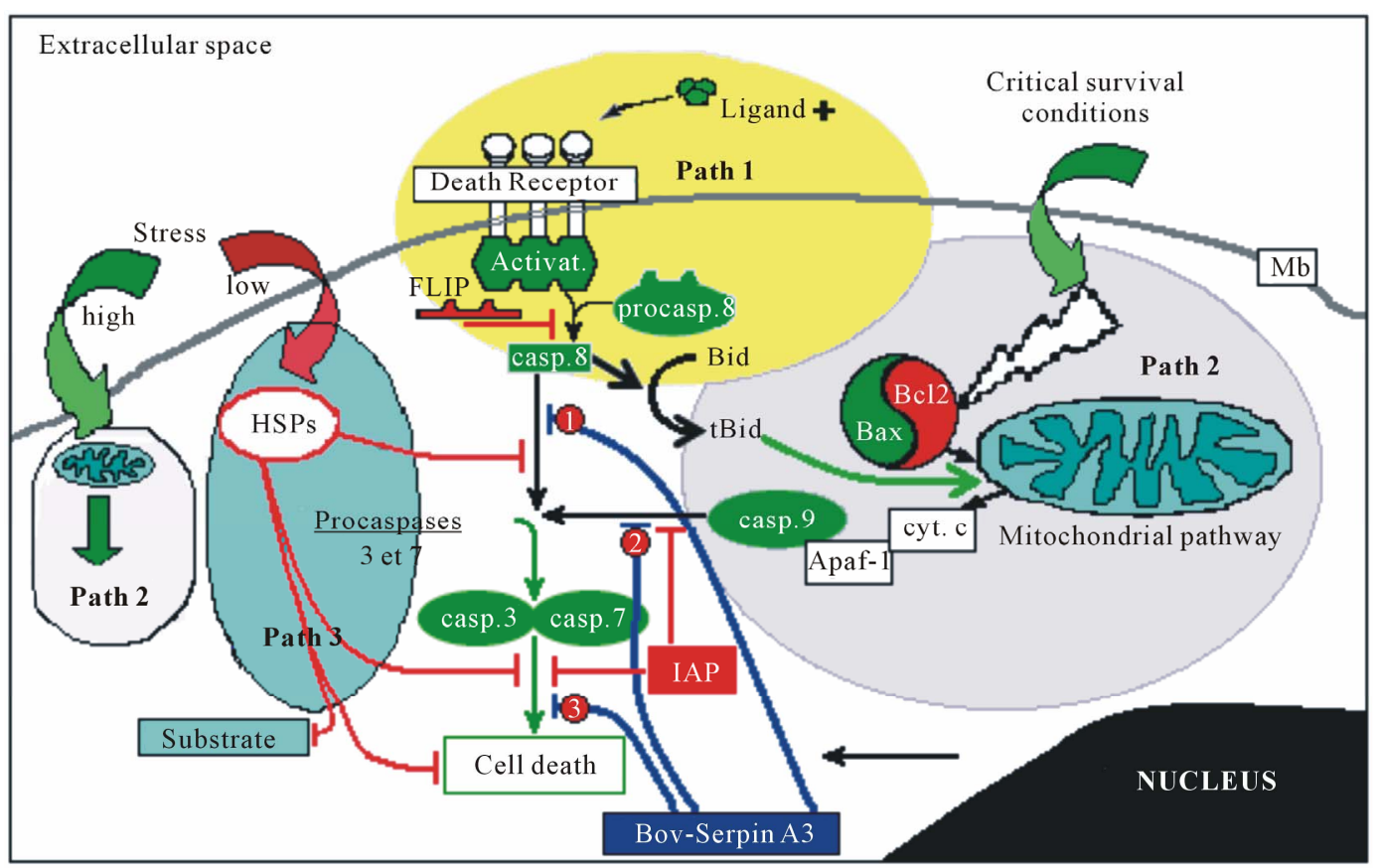

Figure 7. Schematic and simplified diagram summarizing the major regulation points of the apoptotic process. With regards to the extrinsic pathway (Path 1), stimuli will bind to the death receptor inducing the activation of caspases 8 and 10 by association with their activator complexes (DISC or death-inducing signaling complex and CARD or caspase-recruitment domain). Besides the activation of effector caspases, caspase 8 will cleave Bid, a pro-apoptotic member of the Bcl2 protein family, which is at the cross between the intrinsic and extrinsic pathways. Cleaved Bid (tBid) will then initiate the contribution of mitochondria to the cell death process. Activation of caspase 8 by the activator complex can be lowered down by FLIP (FLICE inhibitory protein) a protein competing for binding to the activator complex. Activated caspase 8 will then in turn activate executioner caspases 3 and 7. The apoptotic status of the cell will be comforted by the release from mitochondria of diverse pro-apoptotic components including cytochrome $\mathrm{c}$, a necessary member of the apoptosome complex responsible of the procaspase 9 activation. The only one inhibitor of caspase and hence of apoptosis so far identified in mammals are IAPs (Inhibitor of apoptosis proteins) which targeted initiator caspase 9 and effector caspases 3 and 7 [33]. If these steps failed, the process will continue to its end and lead to cell death and dismantling. The new control pathway reported here, namely the pseudo-irreversible inhibition of caspase by dedicated serpins, affect different step of the apoptotic process. The first control point (1) is the inhibition of initiator caspases, i.e. caspase 8 and probably also caspase 10 . The second (2) is the probable inhibition of caspase 9, another initiator caspase. The third and last point is the inhibition of caspase 3 and, according to recent findings, caspase 7. In the present diagram, we introduce a third path to emphasize the major

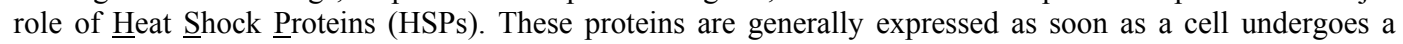
stress to preserve all cell functions by protecting their targets proteins from any structural and/or activity loss. HSPs may have therefore diverse anti-apoptotic actions by protecting the target protein substrates from hydrolysis by caspases and any other proteolytic system of concern and by forming complexes with diverse caspases at different stage of the process thus hindering their function $[34,35]$.

date, members of three protein families have been found capable of ablating caspase activity in vitro and in vivo $[21,24]$. One of these, the Inhibitors of Apoptosis Protein (IAP) family regulates cellular apoptosis by direct caspase inhibition and are conserved from flies to humans [36]. They are potent inhibitors of caspase 3, 7 and 9 [37] and are the only one to be expressed in mammalian tissues and cells. In addition to these endogenous regulators there are virally encoded inhibitors - cowpox virus crmA and baculovirus p35-that are produced early in infection to suppress caspase-mediated host responses [38]. Protease inhibitors generally work by preventing hy- drolysis of substrate by the enzyme, and almost all natural protease inhibitors achieve this by steric hindering access of substrates to the catalytic centre of the protease. Usually, inhibitors dock onto the same sites as substrates on the enzyme surface. By contrast, caspase inhibition by IAPs does not use these conventional mechanisms. To achieve their goal, IAPs block substrate access to the peptidase active site without directly docking into substrate pockets on the enzyme surface allowing hydrolysis of small molecules substrates after IAP binding [24,38].

It was therefore often thought that, for unknown reasons, cystatins or serpins do not seem to have been cho- 
sen for endogenous caspase regulation in eukaryotic cells. This gap now seems to be filled in with the results reported here and invalidating this statement. Indeed, all findings reported clearly demonstrate that eukaryotic cells have in fact developed very efficient pseudo-ireversible caspase inhibitors belonging to the serpin superfamily, a superfamily of inhibitors well known to form pseudo-irreversible complexes with their target peptidases. We further showed here that, in contrast to the cowpox virus crmA, they form SDS-stable serpin/caspases complexes both in vitro and in situ according to recent findings (unpublished data). Such a more radical inhibition of the caspases than IAPs is indeed essential and constitutes probably an absolute prerequisite for a strict and efficient regulation of apoptosis. Because of their ability to inhibit pseudo-irreversibly initiator and effector caspases, such caspase inhibiting serpins might play a central role in apoptosis regulation and, may be also, in inflammatory processes.

\subsection{Role in Muscle Cells Differentiation}

During the process of muscle development, myoblasts proliferate and then undergo differentiation, fusing to form multinucleated myotubes. During the proliferating phase, it was suggested that myoblast are protected against cell death by different still unclear mechanisms. Some authors suggested that this protection is mediated by thrombin [39], a trypsin-like serine peptidase expressed in muscle cells [40] and decreasing significantly the number of apoptotic cells in culture performed in the presence of this peptidase [39].

Because bovSERPINA3s are strong inhibitors of initiator and executioner caspases, their expression in differentiating primary myoblasts was followed by immunohistochemistry using the anti-bovSERPINA3-1 antibody. As depicted in Figure 8, bovSERPINA3 are expressed in proliferating (Figure 8(a)) and in confluent (Figure 8(b)) myoblasts but not in differentiated myotubes (Figure 8(c)). In Figure 8(d), we can observe a reminiscent fluorescence which must be very likely ascribed to myotubes which are still under differentiation. At the end of the 90's, it was suggested that protective action against myoblasts cell death might be ascribed to the synthesis of an unknown apoptosis inhibitory factor [39]. The caspase inhibiting serpins described in this report might be this factor suggesting a real contribution of bovSERPINA3 to cell survival in differentiating primary myoblast, a result in good agreement with the expression pattern of these serpins during the different steps of the process.

\section{CONCLUSION}

This report stress forward that, in contrast to what has
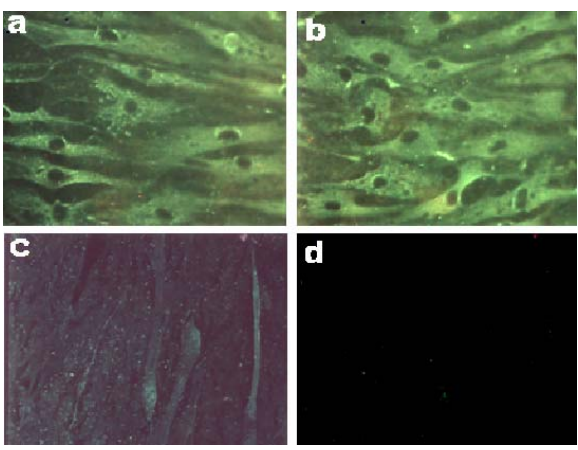

Figure 8. Expression of Bov-SerpinA3 during primary myoblast differentiation. (a) Proliferating myoblasts; (b) Confluent myoblasts; (c) Differentiated myoblasts (myotube); (d) Control with omitted primary antibody. Expression of these serpins was revealed by immunohistochemistry using the polyclonal rabbit antibody raised against Bov-SerpinA3-1 as the primary antibody and a FITC labelled anti-rabbit $\operatorname{IgG}$ as the secondary antibody.

been often recognized, mammalian cells express diverse serpins able to inhibit strongly caspases, a family of proteases responsible for cell dismantling during apoptosis or programmed cell death. In bovine, 8 genes encoding 8 closely related serpins have been identified. As deduced from their RCL sequences, it is clear that six of them are able to inhibit initiator and effector caspases. They are all intracellular and, as they have a signal peptide, they can be exported and this was supported by their particular high concentration in plasma. They are further widely distributed and were present in all tissues and fluids so far examined. All are highly homologous to human SERPINA3, a group comprising one member known as the $\alpha_{1}$-antichymotrypsin, a serpin also highly concentrated in blood and inhibiting strongly elastase. From a practical point of view, these results may offer new fields of research, especially in human where dysfunction of the apoptotic process is known to led to severe pathologies including cancer for which no totally efficient therapy have been so far found [2]. Such caspase inhibiting serpins are not well known and much remains to be done if we expect to better understand their biological functions and their exact role in apoptosis.

\section{ACKNOWLEDGEMENTS}

This work would have not been possible without the Partenariat Hubert Curien Franco-Algérien TASSILI which allowed regular visit to our laboratory of our colleagues from the University of Constantine (Algeria) during the four last years.

\section{REFERENCES}

[1] Taylor, R.C., Cullen, S.P. and Martin, S.J. (2008) Apop- 
tosis: Controlled demolition at the cellular level. Nature Reviews Molecular Cell Biology, 9, 231-241. doi:10.1038/Nrm2312

[2] Hengartner, M.O. (2000) The biochemistry of apoptosis. Nature, 407, 770-776. doi:10.1038/35037710

[3] Sirzen, F., Zhivotovsky, B., Nilsson, A., Bergh, J. and Lewensohn, R. (1998) Higher spontaneous apoptotic index in small cell compared with non-small cell lung carcinoma cell lines: Lack of correlation with Bcl-2/Bax. Lung Cancer, 22, 1-13.

[4] Fuentes-Prior, P. and Salvesen, G.S. (2004) The protein structures that shape caspase activity, specificity, activation and inhibition. Biochemical Journal, 384, 201-232. doi:10.1042/BJ20041142

[5] Philchenkov, A. (2004) Caspases: Potential targets for regulating cell death. Journal of Cellular and Molecular Medicine, 8, 432-444.

[6] Saelens, X., Festjens, N., Vande Walle, L., van Gurp, M., van Loo, G. and Vandenabeele, P. (2004) Toxic proteins released from mitochondria in cell death. Oncogene, 23, 2861-2874. doi:10.1038/sj.onc. 1207523

[7] Annand, R.R., Dahlen, J.R., Sprecher, C.A., De Dreu, P., Foster, D.C., Mankovich, J.A., Talanian, R.V., Kisiel, W. and Giegel, D.A. (1999) Caspase-1 (interleukin-1betaconverting enzyme) is inhibited by the human serpin analogue proteinase inhibitor 9. Biochemical Journal, 3, 655-665.

[8] Law, R.H., Zhang, Q., McGowan, S., Buckle, A.M., Silverman, G.A., Wong, W., Rosado, C.J., Langendorf, C.G., Pike, R.N., Bird, P.I. and Whisstock, J.C. (2006) An overview of the serpin superfamily. Genome Biology, 7, 216. doi:10.1186/gb-2006-7-5-216

[9] Silverman, G.A., Bird, P.I., Carrell, R.W., Church, F.C., Coughlin, P.B., Gettins, P.G., Irving, J.A., Lomas, D.A., Luke, C.J., Moyer, R.W., Pemberton, P.A., RemoldO'Donnell, E., Salvesen, G.S., Travis, J. and Whisstock, J.C. (2001) The serpins are an expanding superfamily of structurally similar but functionally diverse proteins. Evolution, mechanism of inhibition, novel functions, and a revised nomenclature. Journal of Biological Chemistry, 276, 33293-33296. doi:10.1074/jbc.R100016200

[10] Gettins, P.G. (2002) Serpin structure, mechanism, and function. Chemical Reviews, 102, 4751-4804. doi:10.1021/cr010170+

[11] Elliott, P.R., Pei, X.Y., Dafforn, T.R. and Lomas, D.A. (2000) Topography of a 2.0 A structure of alpha1-antitrypsin reveals targets for rational drug design to prevent conformational disease. Protein Science: A Publication of the Protein Society, 9, 1274-1281. doi:10.1110/ps.9.7.1274

[12] Silverman, G.A., Whisstock, J.C., Bottomley, S.P., Huntington, J.A., Kaiserman, D., Luke, C.J., Pak, S.C., Reichhart, J.M. and Bird, P.I. (2010) Serpins flex their muscle: I. Putting the clamps on proteolysis in diverse biological systems, Journal of Biological Chemistry, 285, 24299-24305. doi:10.1074/jbc.R110.112771

[13] Whisstock, J.C., Silverman, G.A., Bird, P.I., Bottomley, S.P., Kaiserman, D., Luke, C.J., Pak, S.C., Reichhart, J.M. and Huntington, J.A. (2010) Serpins flex their muscle: II. Structural insights into target peptidase recognition, polymerization, and transport functions. Journal of Biological Chemistry, 285, 24307-24312. doi:10.1074/jbc.R110.141408

[14] Engh, R., Lobermann, H., Schneider, M., Wiegand, G., Huber, R. and Laurell, C.B. (1989) The S variant of human alpha 1-antitrypsin, structure and implications for function and metabolism. Protein Engineering, 2, 407415.

[15] Ye, S., Cech, A.L., Belmares, R., Bergstrom, R.C., Tong, Y., Corey, D.R., Kanost, M.R. and Goldsmith, E.J. (2001) The structure of a Michaelis serpin-protease complex. Nature Structural \& Molecular Biology, 8, 979-983. doi:10.1038/nsb1101-979

[16] Huntington, J.A., Read, R.J. and Carrell, R.W. (2000) Structure of a serpin-protease complex shows inhibition by deformation, Nature, 407, 923-926.

[17] Herrera-Mendez, C.H., Becila, S., Blanchet, X., Pelissier, P., Delourme, D., Coulis, G., Sentandreu, M.A., Boudjellal, A., Bremaud, L. and Ouali, A. (2009) Inhibition of human initiator caspase 8 and effector caspase 3 by cross-class inhibitory bovSERPINA3-1 and A3-3, FEBS Letters, 583, 2743-2748. doi:10.1016/j.febslet.2009.07.055

[18] Tassy, C., Herrera-Mendez, C.H., Sentandreu, M.A., Aubry, L., Bremaud, L., Pelissier, P., Delourme, D., Brillard, M., Gauthier, F., Leveziel, H. and Ouali, A. (2005) Muscle endopin 1, a muscle intracellular serpin which strongly inhibits elastase: Purification, characterization, cellular localization and tissue distribution. Biochemical Journal, 388, 273-280. doi: 10.1042/BJ20041921

[19] Herrera-Mendez, C.H., Bremaud, L., Coulis, G., Pelissier, P., Sentandreu, M.A., Aubry, L., Delourme, D., Chambon, C., Maftah, A., Leveziel, H. and Ouali, A. (2006) Purification of the skeletal muscle protein Endopin $1 \mathrm{~B}$ and characterization of the genes encoding Endopin $1 \mathrm{~A}$ and 1B isoforms. FEBS Letters, 580, 3477-3484. doi:10.1016/j.febslet.2006.04.099

[20] Pelissier, P., Delourme, D., Germot, A., Blanchet, X., Becila, S., Maftah, A., Leveziel, H., Ouali, A. and Bremaud, L. (2008) An original SERPINA3 gene cluster: Elucidation of genomic organization and gene expression in the Bos taurus 21q24 region, BMC Genomics, 9, 151. doi:10.1186/1471-2164-9-151

[21] Schechter, N.M. and Plotnick, M.I. (2004) Measurement of the kinetic parameters mediating protease-serpin inhibition. Methods, 32, 159-168.

[22] Horvath, A.J., Lu, B.G., Pike, R.N. and Bottomley, S.P. (2011) Methods to measure the kinetics of protease inhibition by serpins. Methods in Enzymology, 501, 223-235. doi:10.1016/B978-0-12-385950-1.00011-0

[23] Dobo, J., Swanson, R., Salvesen, G.S., Olson, S.T. and Gettins, P.G. (2006) Cytokine response modifier a inhibition of initiator caspases results in covalent complex formation and dissociation of the caspase tetramer. Journal of Biological Chemistry, 281, 38781-38790. doi:10.1074/jbc.M605151200

[24] Stennicke, H.R., Ryan, C.A. and Salvesen, G.S. (2002) 
Reprieval from execution: The molecular basis of caspase inhibition. Trends in Biochemical Sciences, 27, 94-101.

[25] Swanson, R., Raghavendra, M.P., Zhang, W.Q., Froelich, C., Gettins, P.G.W. and Olson, S.T. (2007) Serine and cysteine proteases are translocated to similar extents upon formation of covalent complexes with serpins-Fluorescence perturbation and fluorescence resonance energy transfer mapping of the protease binding site in CrmA complexes with granzyme B and caspase-1. Journal of Biological Chemistry, 282, 2305-2313. doi:10.1074/jbc.M609546200

[26] Blanchet, X., Pere-Brissaud, A., Duprat, N., Pinault, E., Delourme, D., Ouali, A., Combet, C., Maftah, A., Pelissier, P. and Bremaud, L. (2012) Mutagenesis of the bovSERPINA3-3 demonstrates the requirement of aspartate-371 for intermolecular interaction and formation of dimers, Protein Science: A Publication of the Protein Society, 21, 977-986. doi:10.1002/pro.2078

[27] Billingsley, G.D., Walter, M.A., Hammond, G.L. and Cox, D.W. (1993) Physical mapping of four serpin genes: Alpha 1-antitrypsin, alpha 1-antichymotrypsin, corticosteroid-binding globulin, and protein $\mathrm{C}$ inhibitor, within a $280-\mathrm{kb}$ region on chromosome I4q32.1. American Journal of Human Genetics, 52, 343-353.

[28] Forsyth, S., Horvath, A. and Coughlin, P. (2003) A review and comparison of the murine alpha1-antitrypsin and alpha1-antichymotrypsin multigene clusters with the human clade A serpins. Genomics, 81, 336-345.

[29] Horvath, A.J., Forsyth, S.L. and Coughlin, P.B. (2004) Expression patterns of murine antichymotrypsin-like genes reflect evolutionary divergence at the serpina3 locus. Journal of Molecular Evolution, 59, 488-497. doi:10.1007/s00239-004-2640-9

[30] Musilova, P., Lahbib-Mansais, Y., Yerle, M., Cepica, S., Stratil, A., Coppieters, W. and Rubes, J. (1995) Assignment of pig alpha 1-antichymotrypsin (AACT or PI2) gene to chromosome region 7q23-q26, Mamm Genome, 6, 445.

[31] Archibald, A.L., Couperwhite, S., Mellink, C.H., Lahbib-Mansais, Y. and Gellin, J. (1996) Porcine alpha- 1-antitrypsin (PI): cDNA sequence, polymorphism and assignment to chromosome 7q2.4q26. Animal Genetics, 27, 85-89.

[32] Lamkanfi, M., Festjens, N., Declercq, W., Vanden Berghe, T. and Vandenabeele, P. (2007) Caspases in cell survival, proliferation and differentiation. Cell Death Differ, 14, 44-55. doi:10.1038/sj.cdd.4402047

[33] O'Riordan, M.X., Bauler, L.D., Scott, F.L. and Duckett, C.S. (2008) Inhibitor of apoptosis proteins in eukaryotic evolution and development: A model of thematic conservation. Developmental Cell, 15, 497-508. doi:10.1016/j.devcel.2008.09.012

[34] Beere, H.M. (2005) Death versus survival: Functional interaction between the apoptotic and stress-inducible heat shock protein pathways. Journal of Clinical Investigation, 115, 2633-2639. doi:10.1172/Jc126471

[35] Arrigo, A.P. (2005) Heat shock proteins as molecular chaperones. Medecine Sciences, 21, 619-625.

[36] Deveraux, Q.L. and Reed, T.C. (1999) IAP family proteins-Suppressors of apoptosis. Genes \& Development, 13, 239-252

[37] Dean, E.J., Ranson, M., Blackhall, F., Holt, S.V. and Dive, C. (2007) Novel therapeutic targets in lung cancer: Inhibitor of apoptosis proteins from laboratory to clinic. Cancer Treatment Reviews, 33, 203-212. doi:10.1016/j.ctrv.2006.11.002

[38] Cassens, U., Lewinski, G., Samraj, A.K., von Bernuth, H., Baust, H., Khazaie, K. and Los, M. (2003) Viral modulation of cell death by inhibition of caspases. Archivum Immunologiae et Therapiae Experimentalis, 51, 19-27.

[39] Chinni, C., de Niese, M.R., Tew, D.J., Jenkins, A.L., Bottomley, S.P. and Mackie, E.J. (1999) Thrombin, a survival factor for cultured myoblasts. Journal of Biological Chemistry, 274, 9169-9174.

[40] Citron, B.A., Smirnova, I.V., Zoubine, M.N. and Festoff, B.W. (1997) Quantitative PCR analysis reveals novel expression of prothrombin mRNA and regulation of its levels in developing mouse muscle, Thrombosis Research, 87, 303-313. 